\title{
Spontaneous pneumopericardium in a patient with COPD
}

\author{
Nilgün YILMAZ DEMIRCi ${ }^{1}$ \\ Nurdan KÖKTÜRK ${ }^{1}$
}

\author{
1 Department of Chest Diseases, Faculty of Medicine, Gazi University, \\ Ankara, Turkey \\ ${ }^{1}$ Gazi Üniversitesi Tıp Fakültesi, Göğüs Hastalıkları Anabilim Dalı, \\ Ankara, Türkiye
}

Pneumopericardium (PPC) is a rare but potentially serious condition that is defined as the presence of air-fluid level in the pericardial sac. It may ocur spontaneously or may be associated with invasive diagnostic and therapeutic procedures, bronchospasm, esophageal disorders and other problems (1). We describe a case of incidentally detected spontaneous PPC, who hospitalized with diagnosis of infectious COPD episode.

A 69-year-old man was admitted for fever and dyspnea associated with productive cough, sputum. He had COPD for five years and was using inhaled bronchodilators. He had a history of 45 pack-year smoking. Also he had hypothyroidism, he was using levothyroxine but he had for gotten to take the drug for two weeks. On admission, his temperature was $38.3^{\circ} \mathrm{C}$, with a respiratory rate of 28 breaths perminute, a pulse of 100 beats perminute, and a blood pressure of $110 / 70 \mathrm{mmHg}$. Breathing sounds were decreased bilaterally. The complete blood cell count on admission revealed a white blood cell count of $18.770 / \mathrm{mm}^{3}$ (neutrophils, $85.7 \%$; lymphocytes, 9.5\%; monocytes, $4.6 \%$; eosinophils, $0.1 \%$; basophils, $0.1 \%$ ), hemoglobin level of $12.0 \mathrm{~g} / \mathrm{dL}$, platelet count of

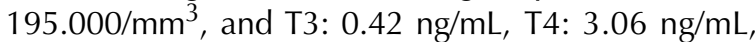

TSH: $20.43 \mathrm{IU} / \mathrm{mL}$. C-reactive protein and procalcitonin was markedly elevated to $292 \mathrm{mg} / \mathrm{L}$ and $0.9 \mathrm{ng} / \mathrm{mL}$ respectively. His anteroposterior chest radiograph revealed cardiomegaly and we observed an air-fluid level at the left heart border (Figure 1). Computed tomography (CT) showed 2 $\mathrm{cm}$ pericardial effusion and air in the pericardial space (Figure 2). There was no evidence of pneumomediastinum. Echocardiogram showed a mild pericardial effusion with no echocardiographic evidence of cardiac tamponade. The patient was man aged conservatively with antibiotics, bronchodilators and he was started on levothyroxine treatment and, subsequently, clinical symptoms, pericardial effusion and air in the pericardial spacere solved with the treatment.

Spontaneous PPC is an uncommon conditionand is usually associated with other simultaneously-

\section{Yazışma Adresi (Address for Correspondence)}

Dr. Nilgün YILMAZ DEMIRCi

Gazi Üniversitesi Tıp Fakültesi, Göğüs Hastalıkları Anabilim Dalı, ANKARA - TURKEY

e-mail: nilgundemirci@gmail.com 


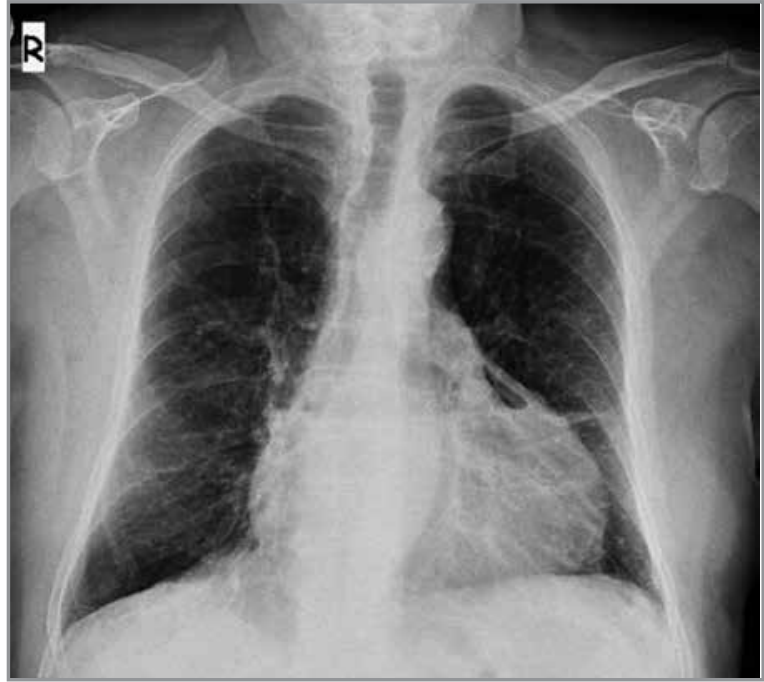

Figure 1. Chest radiograph revealed cardiomegaly and an air-fluid level at the left heart border. occuring air leaks, such as pneumothorax, pulmonary interstitial emphysema, pneumomediastinum, subcutaneous emphys ema and pneumoperitoneum (2).

The clinical signs of spontaneous PPC changes according to amount of air in the pericardial sac. PPC can be asymptomatic or may progress to tension pneumopericardium. Most patients with spontaneous PPC and pneumomediastinum recover spontaneously with in 1 or 2 weeks if the amount of air is mild. Pulmonary barotrauma, tuberculosis, severe cough, asthma, cocaine inhalation, chlorine gas exposure, fistula formation from oesophageal or gastriculcers, emesis and pneumonia can cause spontaneous PPC or pneumomediastinum $(3,4)$.

The pathophysiology of pneumomediastinum involves the pressure gradient between the alveoli and lung interstitium; increased pressure leads to alveolar rupture, resulting in air in the interstitial
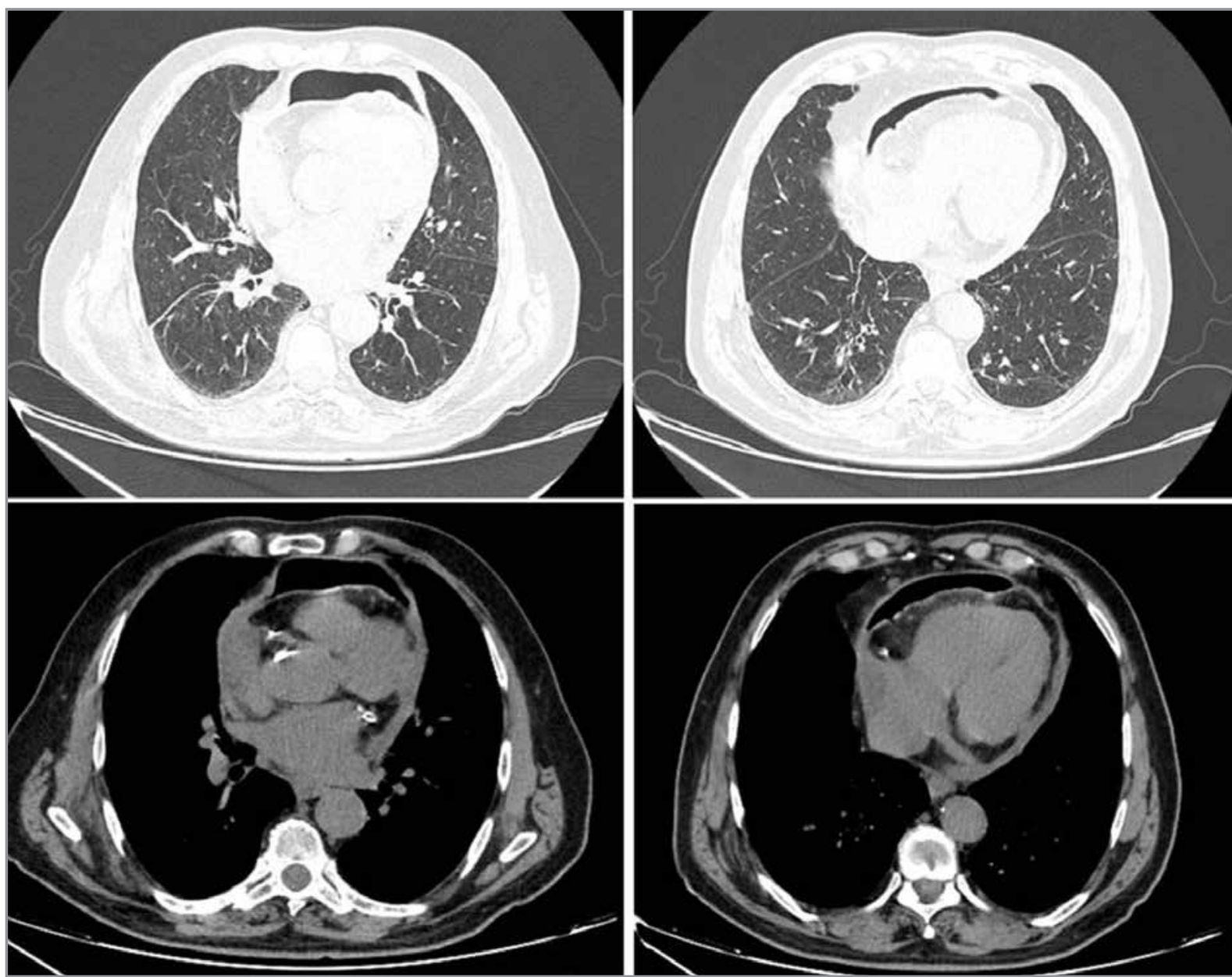

Figure 2. Computed tomography showed $2 \mathrm{~cm}$ pericardial effusion and air in the pericardial space. 
space flowing to ward the mediastinum along the pressure gradient between the lung periphery and mediastinum (5). Pneumomediastinum may be due to leak age of air from cystic lesions (pneumatoceles) caused by ischemic necrosis of vessels or proteases released by activated macrophages. Gas-producing microorganisms as Peptostreptococcus, Bacteroides, Escherichia coli, and Klebsiella species present in the mediastinum as well as rupture of the mucosal barrier of the esophagus or tracheobronchial tree are considered possible mechanisms underlying the development of pneumomediastinum. Pneumopericardium also develops because of a sudden in-crease in intra-alveolar pressure. Other possible causes such as trauma, presence of fistula from neighboring structures, or infection by gasproducing pathogens. An increase in intra-alveolar pressure due to bronchospasms or cough may provoke rupture of some alveoli, with ensuing pneumomediastinum resulting in air crossing the pericardial wall and leading to pneumopericardium. Air may enter the pericardial space via a congenital pleuropericardial connection $(6,7)$. In our patient there was no history of invasive diagnostic or therapeutic procedures but cough may have led to this situation. Although our patient had elevated infective parameters, no pathogen was isolated in culture. And clinical symptoms and air in the pericardial space resolved with the antibiotic treatment.

Pneumopericardium can be diagnosed by conventional chest radiography, CT, or echocardiography (8). We noticed an air-fluid level on chest graph of our patient and after that confirmed by CT.

Pericardial effusion is a known complication of hypothyroidism and is related to the severity and duration of the disease. By extravasation of albumin and inadequate lymphatic drainage exudative pericardial effusion accumulates. Thyroid replacement therapy is necessary over a long period of time and requires close follow-up (9).

\section{REFERENCES}

1. Park, YK, Jung HC, Kim YS, Kim MY, Jo K, Kim Se Y, et al. Spontaneous pneumomediastinum, pneumopericardium, and pneumothorax with respiratory failure in a patient with aids and pneumocystis jirovecii pneumonia. Infection \& Chemotherapy 2014;46:204-8.

2. Suryawanshi P, KlimekJ. Preterm neonate with spontaneous pneumopericardium with out any other associated air leaks. J Clin Diagn Res 2014;8:181-2.

3. Agarwal MP, Giri S, Jain R, Sharma V. Spontaneous pneumopericardium in acute asthma. Int / Emerg Med 2010;3:141.

4. Horvat T, Savu C, Motas C, Tetu M. Pneumopericardiumcomplication of an unknown tuberculosis in a HIV positive patient. Eur I Cardiothorac Surg 2004;26:1043.

5. Cho IY, Kim DM, Kwon YE, Yoon SH, Lee SI. Newly for med cystic lesions for the development of pneumomediastinum in Pneumocystis jirovecii pneumonia. BMC Infect Dis 2009;9:171.

6. Abraham GE $3^{\text {rd }}$, Sumrall BH, Bowling MR. Theairapparent: a rare complication during flexible bronchoscopy. Am J Med Sci 2011;341:243-5.

7. Tsai WC, Lin LJ, Chen JH, Wub MH. A febrile spontaneous pneumopyopericardium International Journal of Cardiology 1996;54:69-72.

8. Iyer VN, Joshi AY, Ryu JH. Spontaneous pneumomediastinum: analysis of 62 consecutive adult patients. Mayo Clin Proc 2009;84:417-21.

9. Shastry RM, Shastry CC. Primary hypothyroidism with pericardial tamponade. Indian I Pediatr 2007;74:580-1. 